\title{
Building social capital in a knowledge-building community: Telementoring as a catalyst
}

\author{
D. Kevin O’Neill, Faculty of Education, Simon Fraser University \\ Introduction: Building the knowledge society
}

For over a decade, Scardamalia, Bereiter and the Knowledge-Building team have pursued a vision of education in which students take a dramatically more active role in their learning. As a result, they become more aware of their own, and others' processes of constructing knowledge. This "knowledge-building" pedagogy (Scardamalia 1991) is enabled by a highly evolved software application called Knowledge Forum ${ }^{\circledR}$, which supports students' efforts in creating, sharing and continuously building upon a rich communal database which reflects their best current understandings of the world, through text, graphics, links, and special sets of markers for different kinds of intellectual contributions (Scardamalia and Bereiter 1994).

Much of both the technical and intellectual work on Knowledge Forum ${ }^{\circledR}$ and its predecessor, CSILE, occurred in the days before wide-area networking and the Internet became widespread. In this context, it was not nearly as tempting as it is today to seek the answers to all of life's questions on the web. As a result, CSILE students learned to trust the collective judgment of their classroom knowledge-building communities, and to enrich these communities through their own efforts. Along with this fierce intellectual independence, they sometimes unwittingly learned a certain degree of irreverence for adult "experts".

This legacy holds many advantages; but it also carries some limitations which deserve attention. Since knowledge-building pedagogy developed in classrooms that were technically isolated from external collaborators (aside from the knowledge-building team), teachers and students did not naturally develop ways to cope with outside collaborators who might be of great help on a daily basis. Neither did they develop ways to take account of the needs that knowledgeable adult collaborators bring. To some extent, this lack of social protocols for engaging routinely with adults limits the ability of teachers and students in new Knowledge Forum classrooms to take advantage of broader community resources that might help them succeed in their efforts. These resources include parent volunteers and other adults who may be willing to serve as mentors for students.

\section{Touching the world outside}

Today, knowledge-building pedagogy is practiced in a world of expertise which is increasingly interconnected; and Knowledge Forum ${ }^{\circledR}$ databases can be made accessible to collaborators all over the Internet. This is a great strength, since Internet access is now common enough in knowledgecentred workplaces, in the dorms and homes of university students and graduates, and in K-12 schools that on any given day it is possible in principle for millions of knowledgeable adults to be directly involved in the learning of millions of children. Needless to say, such interactions do not happen routinely today; but if the right sort of adult-child learning relationships could be made to happen routinely, and under the guidance and direction of professional educators, they have the potential to produce dramatic improvements in educational practice. Rather than firing off questions to "ask-an-expert" services and passively receiving answers, as many students and teachers do today, they might grapple together with ambitious problems of understanding, in the company of adults who would serve as role models, guides and advisors. Working together over extended periods of time, students would be able to engage in the sorts of mentoring relationships that are unfortunately rare in face-to-face settings (Kram 1985; Noe 1988), creating a new kind of computer-mediated "knowledge society" (Scardamalia and Bereiter 1996). 
This type of routine on-line mentoring is quite feasible. However, as things stand, the ask-an-expert model is depressingly more common - in part because it is simpler to integrate into the most common teaching practices than mentoring is. Fortunately, over the past several years my colleagues, collaborators and I have learned a great deal about how to make on-line mentoring, or "telementoring" relationships between K-12 students and adult volunteers successful (O'Neill, Wagner et al. 1996; Harris, Rotenberg et al. 1997; O’Neill and Gomez 1998, November; Harris and Jones 1999; Tsikalas and McMillan-Culp 2000). Today, large programs exist which connect thousands of students and volunteers each year (e.g. Neils, 2001). This work shows that despite the scepticism of those who have never volunteered themselves, average educated adults are quite capable of complementing the efforts of skilled teachers to support ambitious classroom inquiry (see esp. O'Neill, in press). The hope is that with the benefit of further research, and using software tools currently under development in my lab, telementoring relationships can be routinely orchestrated in many schools with about the same level of teacher effort as is needed to organize a field trip.

Contrary to what some assume, the main reasons that more adults do not play the role of telementors more often are not that they are uninterested or incapable of doing so. Large-sample studies have shown repeatedly that all things considered, the best predictor of whether educated, middle-class people do or do not get involved in volunteer activities (at schools or elsewhere) is whether they are asked (Hall, Knighton et al. 1998). Once involved, telementors find that their work with children can carry a variety of unique rewards (O'Neill, Abeygunawardena et al. 2000). The catch is that to reach these rewards, volunteers must overcome some initial uncertainty about what a telementoring relationship looks like and how it works. Unlike career day, science fair and parentteacher night, none of us grew up with on-line volunteering. In part, traditional forms of voluntarism in education are relatively easy to orchestrate simply because they are traditional. Adult volunteers, teachers and students require relatively little coaching to play their respective parts in these activities, because they can all rely on socially ambient knowledge about how these events unfold.

It is reasonable to posit that one day, telementoring relationships will be surrounded with similarly mature traditions. At that point, teachers might be able to put a large volunteer labour force into service at telementoring with the same ease that they can do so for public speaking contests. Census data on volunteering, educational attainment, and Internet access suggest that as many as 2.7 million people might be prepared to serve as telementors in the U.S. and Canada alone (O'Neill and Harris 2000); but for this to happen, teachers and researchers must first develop some social protocols for on-line knowledge-building communities which will support participation by people of diverse ages and expertise. These social routines, and the technological tools that support them, should enable people to figure out where and how to make themselves useful to each other in a shared electronic workspace - ideally in a lightweight and spontaneous manner. For several years I have been working at this problem with a variety of collaborators, and believe that we are making important progress on both conceptual and practical fronts.

Here I will discuss results from recent design experiments carried out in Toronto, involving a new model of telementoring called "mentoring in the open". This model takes advantage of some of the unique affordances of the Knowledge Forum software, and appears to have three important benefits for knowledge-building communities:

- It helps students take advantage of their peers" experiences to understand how "good" mentoring relationships work.

- It enables telementors to scaffold "social comparisons" which can enable learning.

- It enables telementors' to serve as models to catalyze peer support

These advantages will be discussed in detail below. 


\section{Social capital in computer-supported collaborative learning}

To understand what sorts of social routines and technological affordances might best support online knowledge-building communities involving both adults and children, it may help to observe how things work in face-to-face communities where mentoring, apprenticeship, and other muchlauded learning relationships (Resnick 1987; Brown, Collins et al. 1989) occur spontaneously. Scholars have already done considerable work in refining a global sense of the factors that contribute to the health of such learning communities. Recently, sociologist Robert Putnam (2000) offered a thorough historical analysis of community and civic participation in America, including the changes it has seen as technologies like television and the automobile have grown in popularity. Putnam's analysis suggests that many of the factors and functions discussed previously in the literature can be productively viewed as by-products of a broader phenomenon that he and others have referred to as "social capital":

Whereas physical capital refers to physical objects and human capital refers to properties of individuals, social capital refers to connections among individuals - social networks and the norms of reciprocity and trust that arise from them. In that sense social capital is closely related to what some have called "civic virtue". The difference is that "social capital" calls attention to the fact that civic virtue is most powerful when embedded in a dense network of reciprocal social relations. A society of many virtuous but isolated individuals is not necessarily rich in social capital. (Putnam 2000, p. 19)

Previous examinations of age- and expertise-diverse learning communities, both on-line (Bruckman 1998) and off (Jacobs 1961; Harper 1987) suggest that social capital is an inalienable part of what makes authentic learning communities function with a healthy degree of reciprocity and trust, and in a sustainable fashion. For instance, the learning community surrounding the master mechanic Willy, depicted in Douglas Harper's (1987) Working Knowledge, relies on a broad array of interdependent human relationships. Some of these relationships are relatively remote, and bonded to a fee-for-service economy. Clients visit the shop, drop off their inoperative cars or farm machinery, and pay Willy with cash once he has finished repairing them. Deeper, more reciprocal learning relationships coexist with the remote ones - developed through an informal economy involving barter.

Regulars at Willie's shop, like the author Harper himself, make use of Willy's tools and expertise for their own projects, working virtually as Willy's apprentices. In Harper's account, it becomes clear that the friend-apprenticeship and fee-for-service relationships are actually reliant on each other: paying customers depend on barterers to supply the spare parts, odds and ends that Willy uses to do his work for them, while the friend-apprentices rely to some extent on the paying customers to supply the cash needed to buy any tools and supplies that cannot be made from scratch. Finally, on a broader scale the business of the shop itself is sustained because both paying clients and apprentices spread its reputation by word of mouth. All in all, social capital is an important part of what makes the community work.

In a similar way but in a very different context, Jane Jacobs (1961) describes the informal teaching relationships that she observed on the sidewalks of big American cities. These relationships, which serve an important role in socializing children and protecting them from the rigors of growing up, involve participants of all ages - including peers, parents, shop owners and passers-by. This network of relationships relies on a broad-based social awareness that develops partly through sheer proximity, and partly through the mixed use of sidewalks for business and play. This mixture of uses allows learning relationships to be struck up spontaneously, and with very little effort:

People....who have other jobs and duties, and who lack, too, the training needed, cannot volunteer as teachers or registered nurses or librarians or museum guards or social workers. 
But at least they can, and on lively diversified sidewalks they do, supervise the incidental play of children and assimilate the children into city society. They do it in the course of carrying on their other pursuits.... It is folly to build cities in a way that wastes this normal, casual manpower for child rearing and either leaves this essential job too much undone...or makes it necessary to hire substitutes.

Ideally, on-line learning communities should be fostered in such a way as to develop and support a similar degree of spontaneity, and similarly interdependent relationships as is reflected in the examples above. As they illustrate, it is largely the network of relationships in a community, the social capital, that allows it to function well on an ongoing basis. Below I will argue that in the realm of computer-supported collaborative learning, just one clear social role - that of the mentor - can be an important catalyst for the growth of broader social capital. The data discussed below, gathered in the context of fairly typical high school science classrooms, show that when on-line mentoring relationships are carried out in the right kind of shared electronic workspace, they can both benefit from and reciprocally help to build a rich network of learning relationships. Thus, they can contribute not only to individual students' learning, but to the creation and maintenance of the sort of intellectual community required for knowledge-building pedagogy to function well.

\section{Background for this study}

Since 1995, I have been working with teachers and other knowledgeable adults to orchestrate and analyze on-line mentoring relationships for students at the middle and high school levels, primarily in project-based science classes (O’Neill, Wagner et al. 1996; O'Neill and Gomez 1998, November; O'Neill 2001). These telementoring relationships, whose explicit purpose was to facilitate students' work on long-term, open-ended investigations, differed in important ways from the tutoring relationships or ask-an expert services with which many researchers may be familiar. They differed from ask-an-expert services, first, because the long-term dialogue enabled students and adult volunteers to develop complex ideas together over time, rather than simply asking for and passing on existing knowledge. They also differed from tutoring relationships in that they did not assume a particular body of skills and knowledge to be passed from the mentor to the mentee. Rather, they allowed students to bring their emerging problems of understanding to the table, as they progressed in their work. ${ }^{1}$

While my early design experiments in telementoring yielded some useful findings, they also reflected important limitations from the standpoint of spreading constructivist pedagogy. Chief among these limitations was the fact that the research took place in teaching-learning settings in which there was already a strong commitment to inquiry-oriented teaching. Having observed that telementoring could strengthen constructivist teaching in these settings, I began to wonder: could it also help to create a culture of inquiry where one does not already exist?

\section{The research setting and data}

With this question in mind, I embarked on research in two Toronto-area public high schools between 1997 and 1999, in partnership with three relatively traditional science teachers who used variants of the lecture-lab-demo pedagogy familiar to many. Students' work with the Knowledge Forum ${ }^{\circledR}$ software and their telementors was not spread throughout the year, as it would normally be in a Knowledge Forum ${ }^{\circledR}$ classroom, but took place as part of an isolated, 10-week "independent study unit". This was a mandated part of the curriculum in these schools, in which students traditionally write library research essays on their own time. Normally, students get little direct guidance on this work, and produce book-report-like papers which merely summarize the work of published authors. During my partnership with the three teachers, the involvement of several

\footnotetext{
1 The curious can find more detailed descriptions of telementoring, including detailed case studies, elsewhere (O'Neill and Gomez 1998, November; Harris and Jones 1999; O'Neill, Abeygunawardena et al. 2000).
} 
volunteer telementors from relevant graduate programs and other sources enabled them to require more ambitious investigative work from their students, without dramatically increasing their own workload.

The 112 students participating in our design experiments were enrolled in upper-track science and biology courses in grades 9 and 11. These classes were quite racially mixed, with high percentages of nonwhite students in each class; but their past academic success contrasted interestingly with the below-average and at-risk students with whom I had worked in the past (O'Neill and Gomez 1998, November; O'Neill 2001), making these students more averse to academic risk-taking than their less successful counterparts. Some of the implications of this difference will be explored below.

\section{Relations to Previous Research}

Two further points of contrast with my past design experiments which should be mentioned were the teachers' level of technical expertise and the level of Internet access available in their schools. While my primary collaborator in previous work (O’Neill, Wagner et al. 1996) had enough technical expertise to maintain a small lab of computers and student e-mail accounts himself, the teachers involved in the work discussed below were only moderately experienced in using Internet technologies for teaching. Each had used Web Knowledge Forum ${ }^{\circledR}$ for a single curriculum unit per year in the two years prior to this study and had a personal computer at home, but none would consider themselves technically advanced. With regard to Internet access, students' access to computers at school was entirely in a central computer lab, rather than in the classroom itself as had been the case with my past collaborators. Many of the students made up for the poor Internet access at school by working with Knowledge Forum on their own time at home. While home Internet access was not a requirement of participation, $57 \%$ of participating students had web access at home in the 1997/98 school year. In 1998/99, 87\% did.

Finally, the most important contrast between the present work and models of telementoring discussed elsewhere (O'Neill and Gomez 1998, November; Harris and Jones 1999; Tsikalas and McMillan-Culp 2000), is that students did not work with their mentors via private e-mail. After declaring their research interests to their teachers, students were organized into thematic "working groups" of varying sizes: from a single student to 10 or more. "Matches" were made between each of these working groups and a volunteer mentor with related expertise, who oversaw their work, and a "views", or compartment, was set up for each working group within the Knowledge Forum ${ }^{\circledR}$ database to help the research groups organize their efforts. These views were more like movable curtains than walls, however. While each student and mentor had a "home" view in which to place their research notes and communicate with others, these views were open for everyone to read and write in. This new arrangement for telementoring was dubbed "mentoring in the open" (O’Neill and Scardamalia 2000).

The data collected during this design experiment included retrospective interviews with the participating teachers, retrospective surveys completed by students about their telementoring experiences, interviews with a subset of students whose surveys reflected successful and unsuccessful mentoring relationships, semi-structured interviews with the teachers and volunteer mentors, and automatic logs of all students reading behaviour in the Knowledge Forum ${ }^{\circledR}$ databases. A subset of this data will be discussed below.

\section{Building knowledge about knowledge-building relationships}

A previous study of 26 telementoring relationships (O'Neill and Gomez 1998, November), revealed that one of the most important challenges to their success is the limited knowledge of mentoring that children and their mentors bring into the classroom. Unlike mentors in face-to-face settings, telementors are critically dependent on their mentees to make regular and frank reports of their progress; but how are students who have never taken part in a mentoring relationship (as most 
children and adults have not), to know why they should invest the effort required to make one a success? The problem is illustrated vividly by the following exchange between an interviewer and a student involved in the present study:

Interviewer: And what was your understanding of how the mentor would be involved in the project?

Student: Zero at the beginning. I didn't have the slightest clue. I knew I was going to meet a mentor.

Interviewer: What did you think he would do?

Student: Going into it I didn't have a clue if he was going to be able to help, or how the conversations were supposed to go...

\section{Partnership versus service}

One way of understanding students' expectations of inquiry telementoring relationships follows the well-worn tradition of describing mentoring relationships according to the "functions" (types of advice, guidance and support) that mentors offer mentees (see for example Kram, 1985). As part of a survey about their telementoring experiences, I asked the 112 students involved in this work to rate the importance of 10 different mentoring functions in what they would imagine to be the "ideal" telementoring relationship. The 10 functions listed on the survey were:

- Help me come up with a question/idea to investigate

- Ask me questions to help me think about my research

- Answer questions I have about scientific ideas

- Give me background information on my topic

- Give me locations on the Internet where I can find resources to answer my question

- Help me to understand material I read about my topic

- Suggest challenging things for me to do that will improve my research

- Review my work as I go along and help me stay on track

- Suggest specific strategies that will help me get my work done

- Suggest books/magazines/scientific journals that I should read

Factor analysis was used to boil students' desires down to a useful summary measure. The results suggested that for the students, the 10 telementoring functions were divided into two natural kinds (see Table 1). Since Factor 1 includes only those kinds of advice, guidance and help that students normally associate with getting started on an investigation (background information, pointers to Internet resources, references to reading materials, or ideas about viable project topics or questions), I labeled it "inquiry jumpstart". The chief distinction between these mentoring functions and those loading on Factor 2 is that none imply an ongoing relationship or accountability between students and their mentors. In contrast, the functions loading on Factor 2 pointed toward the role of a "prodding partner" who does more than get students started. By asking questions, reviewing students' work, and offering ideas about challenging things that students can do to learn more, the "prodding partner" remains continuously involved in students' learning. 
Table 1: Factors underlying students' ratings of the desirability of 10 mentoring functions

Factor 1

(Inquiry jumpstart)
Factor 2

(Prodding partner)

\begin{tabular}{llll}
\hline Pointers to Internet resources & .83 & Offer challenges & .81 \\
\hline Background information & .73 & Ask questions & .78 \\
\hline Readings & .68 & Review work & .73 \\
\hline Help shape project idea/question & .61 & Help interpret data and learning resources & .67 \\
\hline & & Suggest strategies & .54 \\
\hline & & Explain scientific ideas & .52 \\
\hline
\end{tabular}

Ideally, volunteer mentors should play roles more akin to prodding partners than inquiry jumpstarters, since the hallmark of knowledge-building activity is that over time, adults and children collectively "up the ante" on the problems of understanding they feel themselves accountable to (Bereiter and Scardamalia 1993). This continuous effort to build deeper understanding implies a degree of mutual responsibility among knowledge-building partners, whether adults or children, to respect each others' contributions and to consider taking them to heart - even when it might be troublesome, or create additional work.

On occasion, students with little initial understanding of inquiry mentoring are reflective enough to develop an appreciation of the prodding partner role, from their direct experiences alone. In this interview segment, Nina appears to have developed such an appreciation independently (emphasis added):

Nina: Well I thought [my mentor] was like really great in [my research] area right? So...if I wanted to ask her a question, she would reply [just] like that, right? Then I realized she really wanted us to think.

Interviewer: Uh huh.

Nina: Which is like, hard (laughs).

Unfortunately though, even when mentors try to send signals to students that they would like to play the prodding partner role, many students do not think deeply enough about these signals to overcome the cultural bias toward the jumpstart role. Below, for example, is a segment from an interview with two students assigned to the same telementor. One of the students (Shannon) clearly expected their mentor to play an inquiry jumpstart role, while the other (Will) appears at least willing to accept the idea of a prodding partner:

Interviewer: What was your understanding of how your mentor would be involved in the project?

Shannon: I thought my mentor would be involved more than they were.

Interviewer: OK. So, in what way would you say your mentor was helpful to you, if any?

Will: Well she asked us a lot of questions and made us think about our position...

Interviewer: Yeah?

Will: And she gave us some useful web sites. But sometimes it was too late....

Interviewer: What about you Shannon?

Shannon: Yeah, I would say the most useful information were the web sites she gave us, and sometimes when she responded she would give us some useful information. But it wouldn't be in depth, it would be just her viewpoint of it. So, yeah, she was useful in asking questions to make us think of different ideas to cover, and giving us some other information; but again, it was not good enough for us to use [in our paper].

Interviewer: Okay. So what would you say is the single best piece of advice or guidance that she gave you?

Will: It was probably her questions. 
These quotes reflect a "developmental catch-22" of telementoring (O'Neill and Gomez 1998, November). Given what little students know about mentoring relationships, it is easy for them to abandon them before they get any glimmer of their potential from direct experience. This problem is difficult to overcome because it does not yield easily to direct instruction (O'Neill and Harris 2000). In the past, I have begun telementoring projects by walking students through an example of a "model" telementoring relationship, presenting the correspondence between students and adult volunteers, and highlighting their contributions along the way. While this usually makes students more at ease about the idea of telementoring, they often fail to retrieve the lessons of the case when they become relevant. Given what so many studies have shown about the difficulty of knowledge transfer (Pea 1987), I suspect that knowledge about new sorts of learning relationships, like telementoring, is difficult for children to glean from abstract rules, or from case studies involving alien situations and personalities. This points to the possibility that to really understand how a telementoring relationship works, many students may need to see one unfold between familiar people in familiar circumstances.

\section{Free Model Seeking}

In the "open" arrangement of telementoring orchestrated for this study, students could, and did "peek" into the dialogues their peers were carrying on with their own telementors. This "social translucence", as others have called it (Erickson and Kellogg 2000) allowed students to develop more sophisticated ideas about the kinds of advice and guidance they wanted from their mentors, in a way that appears to be more easily transferable than through rules or cases. In effect, students could self-monitor their performance relative to others. This "free model-seeking" allowed students to emulate the best practices they observed among their peers and peers' mentors. As one student explained in an interview:

Yeah that's what I found [Knowledge Forum ${ }^{\circledR}$ ] really useful for...not just in my [part of the database], but when I looked around...it was nice to see where people were, so I knew if I was ahead or if I was, like, behind a little bit. So...it was nice to see... what other people were doing.

Using the results of the factor analysis discussed above, I constructed two "role scales" reflecting each student's desires for mentoring functions of the "inquiry jumpstart" or "prodding partner" varieties. A respondent's score on each role scale is the sum of their desirability ratings for the functions loading on the corresponding factor. The two role scales are not revealing in themselves, but can be used in combination with other data to test whether our use of the Knowledge Forum ${ }^{\circledR}$ environment helped to defeat the developmental catch-22. If this were true, we would expect students who read more extensively in the database to have higher scores on the prodding partner scale. Wider reading would presumably expose students to more models of mentor and mentee behaviour, and put them in a better position to appreciate the variety of ways that mentoring relationships can be helpful.

The data seem to bear out this hypothesis. As Table 2 shows, none of the Knowledge Forum® note reading measures correlate significantly with the desire for inquiry jumpstart functions (e.g. background information, pointers to Internet resources). This suggests that students who were looking for a quick "information fix" to get their research started rarely scoured the database to find it. On the other hand, students who read extensively in the Knowledge Forum ${ }^{\circledR}$ database were likely to desire the kinds of advice and guidance associated with a prodding partner (e.g. asking useful questions, reviewing work). Correlations were significant between the prodding partner scale and all three database reading measures: reading the notes of one's assigned mentor, of other mentors, and of other students. 
Table 2: Correlations between desired mentor role scales, database reading habits, and judgments of overall satisfaction with the mentor relationship $(*$ indicates $\mathrm{p}<=.05$ )

\begin{tabular}{lccc} 
& Inquiry Jumpstart & Prodding Partner & Satisfaction \\
\hline Student Satisfaction & 0.078 & 0.064 & 1.000 \\
\hline \% Notes Read Overall & 0.122 & $0.320^{*}$ & $-0.227^{*}$ \\
\hline \% Own Mentor's Read & 0.022 & $0.294^{*}$ & 0.005 \\
\hline \% Other Mentors' Read & 0.186 & $0.269^{*}$ & $-0.232^{*}$ \\
\hline
\end{tabular}

While students' judgments of the success of their assigned mentor relationships were not significantly related to the number of their own mentors' notes that they had read, both reading other mentors' notes and reading a high number of notes overall were negatively related to students' overall judgments of the success of their relationships with their assigned mentors. Interviews and observations suggest that the causality involved actually moved in two directions. Some students, who felt that their assigned mentor relationships were not proving helpful, decided to look elsewhere in the database for models of mentor and mentee behaviour that might improve these relationships. Other students, who thought their relationships were going as well as could be expected, learned from casual browsing of the database that they in fact had room for improvement.

These data appear to reflect a kind of "vicarious learning" (Stenning, McKendree et al. 1999). Students who selectively "listened in" on the mentor relationships of their classmates apparently became choosier about what they wanted from telementoring. Whether they were prompted to seek models of good mentor and mentee behaviour by relationships they perceived to be in trouble, or changed their ideas about what "success" meant as a result of casually browsing the database, it seems that the combination of technological affordances and social routines that we used in these design experiments helped some students to short-circuit the developmental catch-22 observed in earlier work.

\section{Using and making social capital in Knowledge Forum ${ }^{\circledR}$}

While the results in Table 2 were encouraging by themselves, a review of the interviews carried out with the students made it clear that there was a more complex and more encouraging story behind the numbers. Perhaps the most impressive facet of the model-seeking undertaken by students in this design experiment was that they were not prompted to do it by either the teachers or myself. Further, there were no marks awarded to students on the basis of the number of notes they read. In fact, the structure of the assignment could be taken to discourage students from reading the work of peers outside their own views, since in most cases, the research undertaken by students in each view was of limited relevance to their peers. This leads one to ask why students would bother to venture outside their "home" views at all.

As I discussed in an earlier paper (O'Neill and Scardamalia 2000), the student interviews suggested that at least part of the model-seeking reflected in the Table 2 was driven by pre-existing relationships among students. In fact, it appears that most of the students did not begin their explorations of the Knowledge Forum database with the intention of learning more about telementoring relationships at all. Several who read notes outside their "home" views appear initially to have done so to see what the "smart kids" were doing, or to "check up" on friends:

Student: I went to [another view in the Knowledge Forum database] and I read some of my friends' notes, just to see how long they were, see what they were writing. I don't know why, but just see what they were doing...

Interviewer: OK. So, what do you think you learned from the stuff you read in the other views? 
Student: I think I just...wanted to see what the students were doing in the other view. A view totally different from ours. Just to see what their conversations were like, and how different from ours.

As this quotation illustrates, students often had difficulty articulating what they learned from observing the mentoring relationships of their peers. Occasionally though, a student was aware of having directly transferred a lesson from another student's mentoring relationship. Below, for example, a young man studying the science of cloning explains how observing a friend's mentor relationship led him to a breakthrough with his own mentor. His friend had taken a risk by probing his mentor about a controversial issue related to his research:

I saw how they related to their mentor, and how they talked. And all I could really do was compare how we did with that. It didn't really apply to the final report or anything. I went to the Anti-aging [view], and my friend there was telling me about how, opposing calmness is a good idea. So in my own view I asked my mentor what his views on cloning are...and I stated my own views. Then, he stated his views. That was pretty helpful. I found out what his bias was. He was against human cloning instead of for it. I thought he would be for it, because he was all into cloning and stuff [in his research], right? But it turns out that he was against human cloning, [while] he was for animal cloning. He said that, you know, there are more benefits from animal cloning. And after reading all these possible bad things that could happen with human cloning, it turned out that I was also for the same view.

Both this and the previous quotation show how students' curiosities about their peers can serve as a natural starting place for the kind of model-seeking necessary to overcome the developmental catch22. Where this curiosity exists, it may serve as an invaluable resource for building social capital in a computer-supported community of inquiry. On the other hand, teachers and researchers should be cautious about assuming that this curiosity exists, or that students will consistently follow through on it. Experimental studies have shown that students' interest in comparing their performance with that of their peers can depend strongly on whether they are oriented toward mastering the task at hand, or merely presenting an appearance of high ability (Butler 1992). Dweck (2000) traces such mastery and ability goals to students' personal theories of intelligence, showing that students with strong beliefs in intelligence as a fixed personal resource (as opposed to one that could be increased) may systematically avoid opportunities to learn. Interview data from this study clearly showed hints of such avoidance in one student:

Interviewer: Did you find that some of the grade 11's responded to what you had to say? Nancy: [Yeah], I was...noticing that they were trying to outsmart us.... They were all like, I don't know. They seemed robotic. Like, the words they used! Interviewer: Huge?

Ahmed: I don't know where they get these words. They're twenty-letter words!

\section{Scaffolding social comparison}

This is not necessarily a lost cause; for I also found some evidence that telementors could help students like Nancy overcome their reticence toward social comparisons. An entirely unexpected helping behavour that emerged from the "open" telementoring scheme involved mentors encouraging social comparison by selectively drawing students' attention to their peers' work. As with students' model-seeking, this was not done under direction from the participating teachers or myself. It simply occurred to our volunteers that it would be an efficient and effective way of helping students to put forward their best effort. Rather than laboriously offering advice to individual students, as they would need to do in a private e-mail correspondence, mentors could save themselves effort and avoid possible ambiguity by helping students appreciate exemplary work by peers. One student explained the helpfulness of this strategy this way: 
Sometimes we won't have enough time to read other people's notes, even though [we know] that might help [us]. But if something was really helpful, [our mentor] would highlight it. She would tell us, "OK, go into Andrea's [note] and see." She would say, "Alright, she did this, and this is what you were supposed to do." "Look into Andrea's, or look into Donna's", or whatever. Like, "she is doing something really well." And when Peter [another student] did his position paper...she really advised us to look through [it]. Like, "this is what you're supposed to be doing." So, she would just encourage us to look through specific [notes] I guess.

\section{Catalyzing peer support}

Another unexpected consequence of telementoring in the open was that some students began to view the support of their peers by analogy to the support of their adult mentors. In effect, the presence and activity of adult mentors in the shared inquiry space validated the efforts of publicspirited students, who might otherwise have been viewed (in this highly competitive cohort) as grandstanding. On occasion, supportive peers were even viewed as taking up slack for mentors who logged onto the Knowledge Forum ${ }^{\circledR}$ less frequently. An example comes from a group of Grade 9 students, who went out of their way to praise the efforts of their "grade 11 mentors" in our interviews. (The interview guide was not written to directly address peer support)

One thing I'd like to add is that the grade 11 's, they were kind of like mentors 'cause...they're only two years older, [but] they're a lot smarter. And they'd also respond to some of my [notes]. One [grade 11] responded to 2 or 3 of my [notes]. He...asked a lot of questions, and he helped me out a lot because he told me "what about this?" and he said, "you should really take this into consideration". [So, the grade 11s] helped out a lot. They were like mentors in a way.

A richer example is provided by a second group of grade 9s. For their independent study, they had chosen to explore the scientific possibility and social consequences of an anti-aging drug that might extend a healthy person's life by 50 years. In the following interview segment, the grade 9s praise an 11th-grader, Sandy. She had chosen the same research agenda, and kept the grade 9s from jumping to conclusions in their work:

Keith: Sandy was a real help. She kept contradicting [me]. Like I'd say, "here, it's here! I found an anti-aging drug!" [And] she said, "no you didn't, it's just a lotion" and stuff like that. And she, she'd always be...

Holly: She was almost like another mentor.

Keith: Yeah, she helped us a lot.

Holly: In the way she acted.

Interviewer: Great, so and, so she responded to your notes and you responded to hers. Did you ever give her advice? Did you ever act like her mentor?

Holly: We tried.

Keith: We tried, but she ah....

Holly: Well I found one site, [at the] University of California or something like that. Some special lab testing of anti-aging stuff, and...I told everyone about it. I posted...a couple of web sites, and this is one of the best ones that I have found. They had actually done testing, I think [on] rats, and the rats had lived $30 \%$ to $40 \%$ longer. That was a good site, so we [all] checked that out.

The other side of the story, as told by Sandy and a fellow 11th-grader, Mark, in a separate interview, reflects a surprisingly munificent outlook toward the grade 9 students:

Interviewer: You shared the same view with grade 9's. How did you feel about that? 
Sandy: I think some of them in our view held up fairly well, some of the grade 9's. Like [in] a couple of the other views...you could tell exactly who were the grade 11's and who were the grade 9's, because...only the grade 11's had made conversation. But our view seemed to be pretty equal between the grade 9's and 11's, [in] how often people wrote stuff, and how intelligent it actually was.

Interviewer: How about you Mark, what did you think?

Mark: I really didn't mind [the grade 9s], because I would try to help them out if I could, if I found the time (laughs). Overall, they were just fine, and I think they were there just to learn, just as I was.

Sandy: I checked out a lot of [web] sites for them. There was this one site, where this [grade 9] went to www.anti-aging.com (laughs), and...

Mark: Yeah, something like that, and I think our mentor was the one that told them that, "Um, this is not reliable at all." (laughs)

Sandy: I was checking out the site, and it said right in there, in the frequently asked questions, it said this is not an anti-aging drug, it just makes you look younger. And with almost everyone of these, like these so-called anti-aging drugs out there, that's all they do, they just make you look younger.

Mark: I think that's the problem they had, judging the reliable sources from the unreliable sources and we tried to help them out if we could.

Sandy: And I don't think they wanted to sit down, put in the time to read the entire site, to see if it was reliable. Which is why I read a lot of sites (laughs).

\section{Discussion}

Students' and mentors' spontaneous efforts toward building social capital, whether intentionally or unintentionally, were encouraging signs in an academic environment where students typically cling to traditional pedagogy and behave in an individualistic fashion. They give us hope that the knowledge society is indeed feasible. A natural next step in this research will be to design ways of actively encouraging and more rigorously observing the capital-building behaviours described above. While carrying out this work, we will need to be mindful of two countervailing cultural forces that are already becoming clear in our data. It may be useful to elaborate on these here.

\section{Cultural stereotypes of "experts"}

One of the cultural forces is the idea that learning discourse with mentors makes learning discourse with fellow students unnecessary. This idea, apparently based on a stereotype of "experts" that some students carry into the classroom, stands behind the words of one of our grade 11 students:

Eric: It wasn't clear to me that we could interact with the grade 9's until later.... It was basically you talk to the mentor, the mentor talks to you, and if [an]other student has a good valid point, you'd mention his name [in your own note] but you wouldn't be directly talking to that person. You'd be like, "Well, Andrew had a really good point and I want to know why, blah, blah, blah...." But then, it's never me to [my fellow student], him to someone. It's never a debate like that.

Interviewer: Hmm. Did you think that you were not allowed to do that?

Eric: Oh, it's not that. It's just there's no encouragement do that. I don't know, it didn't seem like there's a reason to. I sort of threw that off, because, you know, why talk to your fellow students, when you [can] talk to an expert, right?

Charles: So...I don't think that was really thought of. My friend, Grant (he's one of the other students) he was directed to one of...the people in his view.... He told me that they [had] a lot of [discussion], where she was giving him a lot of points and, you know...he was giving.... lot of responses directly to her. But in our view it didn't seem to happen. We just, you know...like Eric said, maybe mention the person's name in, in another note 
to our mentor...but it was never really a debate between any of us students by ourselves. (Emphasis added.)

It is the impoverished idea of expertise embodied in this statement that, for years, has led me to discourage my teacher collaborators from using the word "expert" to describe volunteer telementors to their students. To some, the word "expert" appears to denote someone who holds all the answers, and who, as a volunteer, should be ready and willing to dispense them in ways that would be antithetical to constructivist teaching - truncating an inquiry that might succeed independently. This set of expectations also leads my collaborators and I to avoid using the word "help" to describe what mentors are expected to do for their mentees. Instead, our orientations for students describe the mentors' role in providing "advice" and "guidance" — not information, or answers, or knowledge.

Thankfully, not all students this age appear to hold the backward conception of expertise that Eric did. The following quotation comes from an interview with two young women in the present study, who were studying in vitro fertilization under the guidance of an undergraduate in exercise science:

Interviewer: I haven't read absolutely everything in your view yet, but I think I read somewhere, where one of you asked her [your mentor] what her background was with in vitro fertilization.

Joan: Yeah I think that was...

Francis: That was one of us.

Joan: It was either me or you.

Interviewer: And she said, "this is not something that I do for a living, but I have studied about it." Did [it] matter to any of you that she wasn't a world expert on this?

Francis: No.

Joan: No we just wondered why she, like...

Francis: What [area] she was in [professionally].

Joan: Yeah exactly. It wasn't really like, "Well, if you're not qualified we don't want you here."

Interviewer: (laughs)

Joan: We just wanted to know what [she] had done with it before.

Anna: As long as she knows more than I do about it.

Joan: Yeah, exactly.

This more enlightened perspective notwithstanding, the dichotomy that may be assumed by some students - perhaps most - between learning from peers and learning from elders presents a serious problem for anyone with ambitions to build a learning community that deserves its name. Perhaps the main challenge resides in helping students to understand the distinction made by Scardamalia and Bereiter (1993) between an expert and an "expertlike novice" — someone who knows less than an expert would on a particular subject, but tackles problems in a way that is mastery oriented, and likely to deepen her understanding. Ideally, mentors possess some knowledge that is helpful in getting their mentees over unproductive "snags" and directly to the point of an inquiry; but their greater value lies in the guidance they offer in defining and approaching problems.

\section{Genres of learning discourse}

Another vexing problem, related to the one above, is manifest in the ways that the teachers involved in our recent work chose to limit their participation in telementoring discourse. In the design experiments discussed above, the three participating teachers made a point of reading the database throughout the project to keep track on their students' progress; but with rare exceptions, they only chose to contribute notes to a few select views that had been set up largely for administrative purposes. While my interview data do not shed any light on this issue directly, I suspect the 
teachers had a difficult time thinking about how they might contribute to the discourse, because they didn't know what a productive three-way (teacher-student-mentor) dialogue ought to look like. What genre of learning discourse would it resemble? A debate? A didactic exchange like the Initiation-Response-Evaluation sequence common in lecture instruction (Mehan 1978)? A "Q \& A", like a radio interview with a professor after a major news event?

One problem is that each of these familiar genres usually assume no more than two participants. Regrettably, I had no examples of productive three-way telementoring discourse to share with my collaborating teachers, since in my past work teachers had merely monitored the telementoring dialogues of their students, not gotten involved in them directly. Providing appropriate models and advice to teachers on this score, in a form that they can easily use, is another important challenge to be faced in future work.

\section{Coda}

Despite these ongoing challenges, I am encouraged by the promise that telementoring appears to hold for catalyzing the growth of social capital in a knowledge-building community - even one whose participants are traditionally risk-averse and individualistic in their lives at school. Since peer-to-peer learning is an essential component of knowledge-building pedagogy, this is vital. In the design experiments discussed above, adult volunteer mentors managed to contribute to the growth of social capital without any explicit encouragement or instruction, and sometimes without even intending to. Both the mentors' encouragement of social comparisons among students, and their catalysis of peer support emerged spontaneously from a social-technical arrangement that facilitated unplanned, vicarious learning between peers. This suggests that telementoring may prove a valuable tool in helping knowledge-building pedagogy take root in challenging new settings.

With respect to the larger vision of the knowledge society - millions of adults and millions of children inquiring together routinely - there is admittedly a long way to go. But this study offers a glimpse of the power that a single clear social role, that of the mentor, can have to help build and sustain an age-diverse, on-line learning community. Through her actions, a mentor helps constrain the dauntingly wide prospects for collaboration that a large number of participants presents, offering the student some certainty about where to begin making contributions that will be valued. From there, any kind of outward growth is possible.

\section{Acknowledgements}

I gratefully acknowledge the financial support of the James S. McDonnell Foundation, the Natural Sciences and Engineering Research Council of Canada, the Office of Learning Technologies, Human Resources Development Canada, and Simon Fraser University for this work. I would also like to convey my thanks to the CSILE/Knowledge-Building team at OISE/UT for their ongoing support and comradeship, and especially to Kirk Perris for his assistance in conducting the student interviews discussed here.

\section{References}

Bereiter, C. and M. Scardamalia (1993). Surpassing ourselves: An inquiry into the nature and implications of expertise. La Salle, IL, Open Court.

Brown, J. S., A. Collins, et al. (1989). "Situated cognition and the culture of learning." Educational researcher 18(1): 32-42.

Bruckman, A. (1998). "Community support for constructionist learning." Computer supported cooperative work 7: 47-86. 
Butler, R. (1992). "What young people want to know when: Effects of mastery and ability goals on interest in different kinds of social comparisons." Journal of Personality and Social Psychology 62(6): 934-943.

Dweck, C. S. (2000). Self-theories: Their role in motivation, personality and development. Philadelphia, Psychology Press.

Erickson, T. and W. A. Kellogg (2000). "Social translucence: An approach to designing systems that support social processes." ACM Transactions on Computer-Human Interaction 7(1): 59-83.

Hall, M., T. Knighton, et al. (1998). Caring Canadians, involved Canadians: Highlights from the 1997 national survey of giving, volunteering and participating. Ottawa, Canada, Statistics Canada.

Harper, D. (1987). Working knowledge: Skill and community in a small shop. Chicago, University of Chicago Press.

Harris, J., L. Rotenberg, et al. (1997). Results from the Electronic Emissary Project: Telementoring lessons and examples. [On-line]. Available: http://www.tcet.unt.edu/pubs/em/em01.pdf, Texas Center for Educational Technology.

Harris, J. B. and G. Jones (1999). "A descriptive study of telementoring among students, subject matter experts, and teachers: Message flow and function patterns." Journal of research on computing in education 32(36-53).

Jacobs, J. (1961). The death and life of great American cities. New York, Vintage Books.

Kram, K. E. (1985). Mentoring at work: Developmental relationships in organizational life. New York, University Press of America.

Mehan, H. (1978). "Structuring school structure.” Harvard Educational Review 48(1): 32-64.

Noe, R. A. (1988). "An investigation of the determinants of successful assigned mentoring relationships.” Personnel Psychology 41: 457-479.

O’Neill, D. K. (2001). Enabling constructivist teaching through telementoring. Computers in the delivery of special education and related services: Developing collaborative and individualized learning environments. L. J. Krueger. Binghamton, NY, The Haworth Press: 33-58.

O'Neill, D. K. (in press). "Knowing when you've brought them in: Scientific genre knowledge and communities of practice." The Journal of the Learning Sciences.

O’Neill, D. K., H. Abeygunawardena, et al. (2000). The Telementor's Guidebook: A field guide to supporting student inquiry on-line. Ottawa, Office of Learning Technologies, Human Resources Development Canada.

O’Neill, D. K. and L. M. Gomez (1998, November). Sustaining mentoring relationships on-line. ACM Conference on Computer-Supported Cooperative Work, Seattle, WA, Association for Computing Machinery.

O’Neill, D. K. and J. B. Harris (2000). Is everybody happy? Bridging the perspectives and developmental needs of participants in telementoring initiatives. annual meeting of the American Educational Research Association, New Orleans, LA.

O'Neill, D. K. and M. Scardamalia (2000). Mentoring in the open: A strategy for supporting human development in the knowledge society. ICLS 2000: International Conference on the Learning Sciences, Ann Arbor, MI, Lawrence Earlbaum Associates.

O’Neill, D. K., R. Wagner, et al. (1996). Online mentors: Experimenting in science class. Educational Leadership. 54: 39-42.

Pea, R. D. (1987). "Socializing the knowledge transfer problem.” International Journal of Educational Research 11: 639-663. 
Putnam, R. D. (2000). Bowling alone: The collapse and revival of American community. New York, Simon \& Schuster.

Resnick, L. B. (1987). "Learning in school and out.” Educational Researcher 16(December): 1320.

Scardamalia, M., \& Bereiter, C. (1991). "Higher levels of agency for children in knowledge building: A challenge for the Design of new knowledge media." The Journal of the Learning Sciences 1(1): 37-68.

Scardamalia, M. and C. Bereiter (1994). "Computer support for knowledge-building communities." Journal of the Learning Sciences 3(3): 265-283.

Scardamalia, M. and C. Bereiter (1996). Engaging students in a knowledge society. Educational Leadership. 54: 6-10.

Stenning, K., J. McKendree, et al. (1999). Vicarious learning from educational dialogue. Computer Support for Collaborative Learning, Atlanta, Georgia.

Tsikalas, K. and K. McMillan-Culp (2000). Silent Negotiations: A case study of roles and functions utilized by students, teachers and mentors in project-based, telementoring relationships. International Conference of the Learning Sciences, Ann Arbor, MI, Lawrence Erlbaum. 